\title{
Lymphocytic lymphoma recurring in multiple endobronchial sites
}

\author{
DANIEL E BANKS, ROBERT M CASTELLAN, AND DAVID J HENDRICK
}

From the Pulmonary Disease Section, West Virginia University School of Medicine, and Division of Respiratory Disease Studies, National Institute for Occupational Safety and Health, Morgantown, West Virginia, USA

\begin{abstract}
Although malignant lymphoma frequently involves intrathoracic organs at some time during its course, endobronchial nodular lesions are extremely rare. We report a case of poorly differentiated lymphocytic lymphoma in which relapse was characterised by multiple endobronchial nodules. This pattern of progression has been recorded only once previously in non-Hodgkin's lymphoma.
\end{abstract}

\section{Case report}

A 64-year-old man was admitted to West Virginia University Hospital in July 1974 for evaluation of a left inguinal mass of three months' duration and a more recently enlarged right axillary mass. Biopsy at both sites showed diffuse poorly differentiated lymphocytic lymphoma. Hie was subjectively well and physical examination was otherwise normal.

Laboratory data showed a haemoglobin of 15.0 grams, haematocrit of $43 \%$, white blood cell count of 6200 with $41 \%$ lymphocytes, $2 \%$ eosinophils, $53 \%$ neutrophils, and $4 \%$ monocytes. Bone marrow aspirate and biopsy, multiphasic blood analysis, chest radiograph and liver/spleen scan were interpreted as normal.

The patient was considered to have stage IIIA poorly differentiated lymphocytic lymphoma, and treatment was begun with vincristine, prednisone, and streptonigrin (Acute Leukaemia Group B Protocol for stage III and IV lymphoma). A complete clinical remission was achieved within two months. Maintenance therapy, consisting of intermittent cyclophosphamide, prednisone, and vincristine, was discontinued in September 1976 because there was no evidence of persisting disease.

In March 1978 the patient developed enlargement of the left tonsil. Biopsy revealed recurrent lymphoma and chemotherapy with intermittent cyclophosphamide, prednisone, and vincristine was reinitiated without response. In July 1978 chemotherapy was stopped and radiotherapy to the left side of Waldeyer's ring was begun. The mass rapidly resolved.

In August 1978 he developed a low grade fever, breathlessness, and a minimally productive cough. Physical examination revealed bilateral basal crackles

Address for reprint requests: Dr Daniel E Banks, Division of Respiratory Disease Studies, National Institute for Occupational Safety and Health, 944 Chestnut Ridge Road, Morgantown, West Virginia 26505, USA. without wheezing. Neither the liver nor spleen were $\omega^{J}$ palpable nor were there enlarged peripheral lymph $\vec{\circ}$ nodes.

The chest radiograph showed prominence of the right hilum, partial collapse of the middle lobe, ando multiple nodular infiltrates $(1-2 \mathrm{~cm}$ in diameter) in both lung fields (figs 1 and 2).

Fibreoptic bronchoscopy showed multiple whitish nodules scattered throughout the trachea and right and left mainstem bronchi. Most measured 0.5 to $1.0 \mathrm{~cm}$ in diameter. They nearly occluded the right $\overrightarrow{0}$ upper, middle, and left upper lobe orifices. Biopsies 0 taken from several nodules in both mainstem bronchi. revealed poorly differentiated lymphocytic lymphoma, with the same histological characteristics as the inguinal and axillary nodes.

The patient was treated with intermittent predni-ฏ sone, adriamycin, and CCNU. Chest radiographic $\stackrel{\circ}{\mathbb{D}}$ abnormalities resolved completely within six weeks. $\stackrel{\varrho}{\Rightarrow}$ Six months after this change of therapy the patiento was symptom-free and without objective signs of 3 lymphoma.

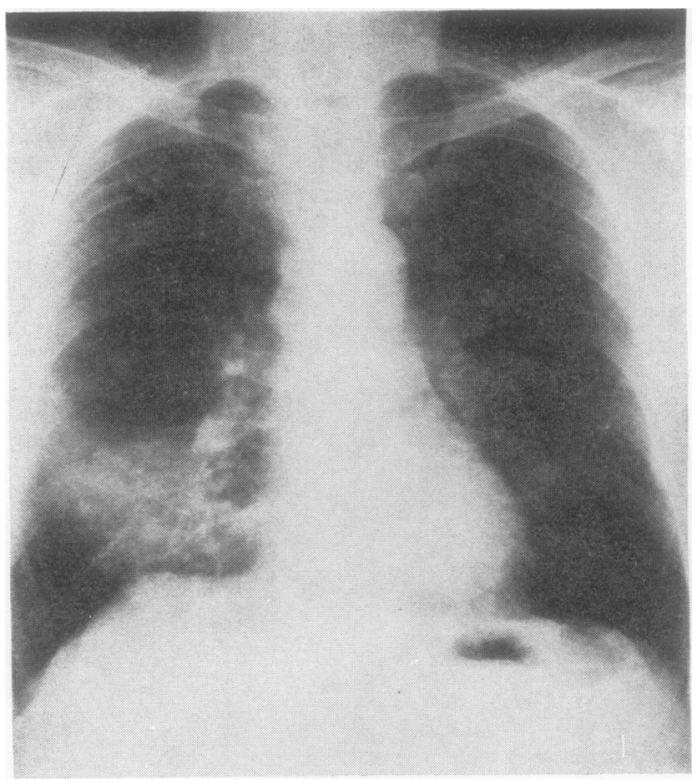

Fig 1 Posteroanterior view showing nodular infiltrates and right hilar prominence. 


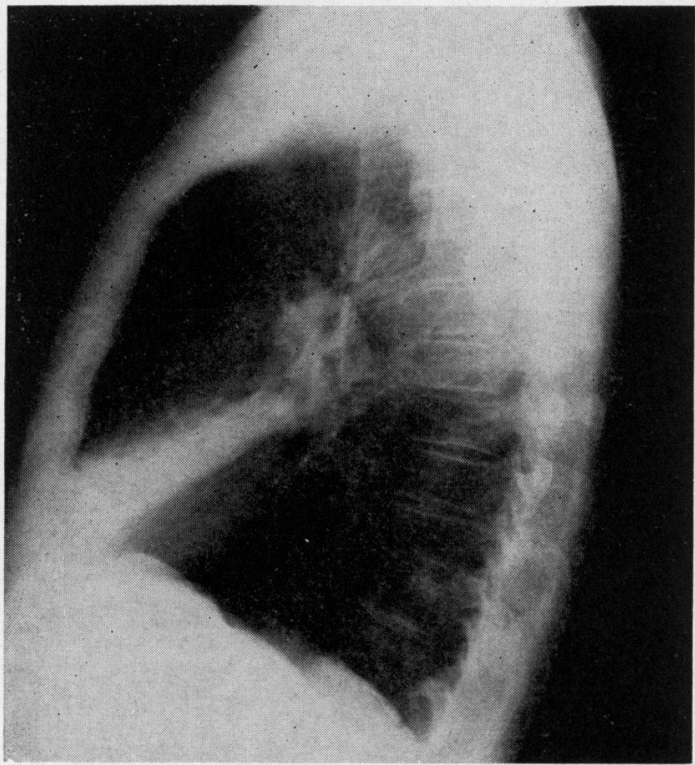

Fig 2 Lateral view showing hilar prominence and partial middle lobe collapse.

\section{Discussion}

Clinically significant bronchial obstruction in patients with lymphoma is usually the result of compression by peribronchial lymph nodes, but rarely may be the consequence of occlusion by endobronchial lymphomatous lesions.

The pathological features of endobronchial lymphoma were first discussed in the English literature by Moolten in $1934 .^{1} \mathrm{He}$ described diffuse plaques and ulcerations, which he termed "granulomatous panbronchitis," in eight cases of Hodgkin's disease studied after death. In addition, endobronchial nodules were evident on gross inspection of the large airways in three of these cases, one of which was remarkable because of complete obstruction of a large bronchus.

The infrequency with which lymphoma occurs endobronchially was documented in a necropsy study of Vieta and Craver, ${ }^{2}$ who reported no nodular lesions in the bronchi of 106 cases of lymphoma. Mucosal plaques and ulcerations were found in the large bronchi in five of 51 cases of Hodgkin's disease, but in none of 55 cases of non-Hodgkin's lymphoma. In another study, Filly et $a l,{ }^{3}$ using whole lung tomograms, documented only one endobronchial mass in 300 untreated patients with lymphoma. Review of subsequently published literature reveals that Moolten's "granulomatous panbronchitis," although an occasional feature of Hodgkin's disease, does not seem to occur in non-Hodgkin's lymphoma, and that endobronchial nodules are rare in all types of lymphoma.

Excluding several cases reported as "primary lymphoma of the lung," we are aware of only 14 cases reported in the English literature in which biopsy of nodular endobronchial lesions was indicative of lymphoma. Of these, seven were cases of Hodgkin's disease, ${ }^{45}$ five of lymphosarcoma, ${ }^{67}$ and two were classified as malignant lymphoma.?

In only five cases have lymphomatous nodules been reported in multiple endobronchial sites. Four were cases of Hodgkin's disease, of which two were diagnosed by bronchoscopic biopsy, ${ }^{45}$ and two at necropsy. ${ }^{18}$ The remaining case was of lymphosarcoma." At bronchoscopy, "multiple polypoid lesions" were seen in the trachea and both mainstem bronchi. Evidence of airway obstruction was not recorded.

In the case we described there was airway obstruction and this prompted bronchoscopy. Multiple endobronchial tumors were seen, making bronchogenic carcinoma an improbable cause of the lobar collapse, despite the increased incidence of this tumor in patients treated for lymphoma. ${ }^{9}$ Biopsies confirmed recurrent lymphoma which had been suspected initially because of the nodular infiltrates noted on the chest radiograph. It is possible that the previous involvement of Waldeyer's ring might also have been significant in this respect.

\section{References}

1 Moolten SE. Hodgkin's disease of the lung. $A m ~ J$ Cancer 1934; 21:253-94.

2 Vieta JO, Craver LF. Intrathoracic manifestation of lymphomatoid diseases. Radiology 1941; 37: 138-59.

3 Filly RF, Blank N, Castellino RA. Radiographic distribution of intrathoracic disease in previously untreated patient's with Hodgkin's disease. Radiology 1976; 120:277-81.

4 Donlan DK Jr, Reid JW. Endobronchial Hodgkin's disease. JAMA 1978; 239:1061-2.

5 Gregory JJ, Ribaudo CA, Grace WJ. Endobronchial Hodgkin's disease. Ann Intern Med 1965; 62:579-86.

6 Dawe BJ, Woolner LB, Parkhill EM, McDonald JR. Cytological studies of sputum, secretions and serous fluids in malignant lymphoma. A $\mathrm{J}$ Clin Path 1955; 25:480-8.

7 Samuels ML, Howe DC, Dodd GD, Fuller LM, Shullenberger CC, Leary WL. Endobronchial malignant lymphoma: report of five cases in adults. $A J R$ 1961; 85:87-95.

8 Vaughn BF. Endobronchial Hodkgin's disease. Br J Radiol 1958; 31:45-7.

9 Libshitz HI, Zornosa J, McLarty JW. Lung cancer in chronic leukemia and lymphoma. Radiology 1978; 127:297-300. 